\title{
Recent patent applications in the area of genomics
}

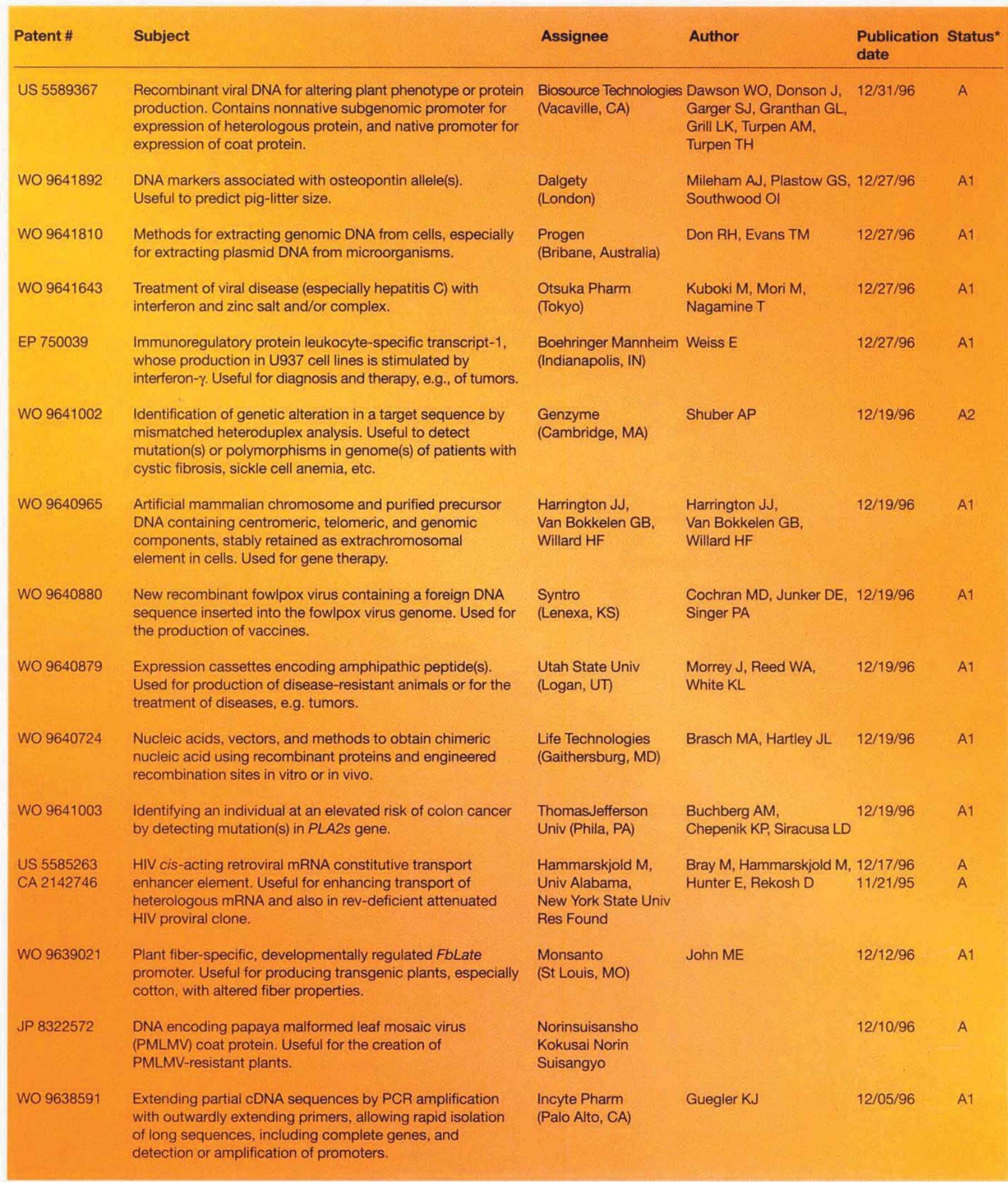

Source: Derwent Information, McLean, VA. "The patents in the table are pending. The status of each application is slightly different from country to country. For further details, contact Derwent scientific and patent information at Derwent North America, 1420 Spring Hill Road, Suite 525, McLean, VA 22102. Tel: 1 (800) DERWENT (info@derwent.com). 